\title{
Dengue bites India
}

$\mathrm{D}$ engue, a mosquito-borne and potentially fatal viral disease, has emerged as a huge threat in India, where the number of cases more than doubling in just one year.

The latest estimates by the Ministry of Health and Family Welfare suggest that in 2008, India recorded 12419 cases of Dengue, up from 5534 case in 2007. Delhi alone recorded 1307 cases of Dengue in 2008, up from 548 in 2007.

Four Indian states, Punjab, Haryana, West Bengal, and Gujarat, have been the worst hit by Dengue, with Punjab reporting 4349 cases, and Haryana, West Bengal and Gujarat reporting 1137, 1050 , and 1023, respectively.

Despite the substantial increases, the fatality rate for Dengue decreased to $0.6 \%$ from $1.25 \%$. Experts believe this trend means the Indian health care system is tackling the situation efficiently.

"Previously, patients with Dengue couldn't receive proper treatment at the right time," says Swapan Jana, secretary of the Society for Social Pharmacology, a nongovernmental organization.

"Now, the Indian health care system has grown up, and an early diagnosis and prompt treatment for Dengue [is] possible, which is why there is a decline in the death rate despite the increase in the case numbers."

Indian Health Minister Anbumani Ramadoss has blamed climate change for Dengue outbreak. Recent years have been the warmest since 1860 . But Jana says that while climate change may be a factor, "it is also a fact that Dengue is a viral disease transmitted in humans by mosquitoes. These figures suggest that there has been a definite lack in controlling these mosquito vectors."

To reduce the Dengue cases, Jana suggests strengthening the vector-control machineries in the Indian health care system - by spraying for mosquitoes, using chemicals to kill mosquito larvae, and by emptying standing water from containers or covering them to prevent mosquitoes from laying eggs. - Sanjit Bagchi MBBS, Kolkata, India

DOI:10.1503/cmaj.090255 